Case Reports in
Gastroenterology
Case Rep Gastroenterol 2021;15:100-107

DOI: 10.1159/000511762

Published online: February 1, 2021

(C) 2021 The Author(s)

Published by S. Karger AG, Basel www.karger.com/crg

This article is licensed under the Creative Commons Attribution-NonCommercial 4.0 International License (CC BY-NC) (http://www.karger.com/Services/OpenAccessLicense). Usage and distribution for commercial purposes requires written permission.

\title{
Diffuse Gallbladder Adenomyomatosis with an Inflammatory Complication in an Adult
}

\author{
Van Trung Hoang ${ }^{a}$ Hoang Anh Thi Van ${ }^{a}$ Thanh Tam Thi Nguyen ${ }^{b}$ \\ Vichit Chansomphou ${ }^{c}$ Cong Thao Trinh ${ }^{d}$ \\ aDepartment of Radiology, Thien Hanh Hospital, Buon Ma Thuot, Vietnam; \\ bepartment of Radiology, Hue University of Medicine and Pharmacy, Hue, Vietnam; \\ 'Department of Radiology, Savannakhet Medical-Diagnostic Center, Kaysone \\ Phomvihane, Laos; ${ }^{d}$ Department of Radiology, Hue Central Hospital, Hue, Vietnam
}

\section{Keywords}

Cholecystitis · Diffuse thickened gallbladder wall · Intramural diverticulosis · Gallbladder adenomyomatosis · Rokitansky-Aschoff sinuses

\begin{abstract}
Gallbladder adenomyomatosis (GA) is a benign alteration of the gallbladder wall. There are three types involved: segmental, fundal, and diffuse pattern; the last type is very rare. Ultrasound is the imaging method of choice for diagnosing that shows Rokitansky-Aschoff sinuses with cholesterol deposition creating comet-tail artifacts. Asymptomatic GA does not require surgery in case there are no malignant lesions defined by imaging diagnosis. We present the rare case of a 51-year-old man who was admitted to hospital due to abdominal pain concomitant with inflammatory syndrome. Imaging and histological findings were appropriate to diagnose diffuse GA and complication of cholecystitis.

(C) 2021 The Author(s)

Published by S. Karger AG, Basel
\end{abstract}

Van Trung Hoang
Department of Radiology, Thien Hanh Hospital
17 Nguyen Chi Thanh Street, Buon Ma Thuot 630000 (Vietnam)
dr.hoangvantrungradiology@gmail.com

Cong Thao Trinh
Department of Radiology, Hue Central Hospital
16 Le Loi Street, Hue 530000 (Vietnam)
thaotrinh2911@gmail.com




\section{Case Reports in Gastroenterology}

\begin{tabular}{l|l}
\hline Case Rep Gastroenterol 2021;15:100-107 \\
\hline DOI: 10.1159/000511762 & $\begin{array}{l}\text { @ 2021 The Author(s). Published by S. Karger AG, Basel } \\
\text { www.karger.com/crg }\end{array}$ \\
\hline
\end{tabular}

Hoang et al.: Diffuse Gallbladder Adenomyomatosis with an Inflammatory Complication in an Adult

\section{Introduction}

Gallbladder adenomyomatosis (GA) is a benign acquired lesion whose feature is a thickened gallbladder wall containing small bile-filled cystic spaces. Jutras [1] described GA for the first time in 1960 and after that its case reports increased [2]. Previously, there were many terms used to refer to this condition, such as cystic cholecystitis, adenomyoma, cholecystitis glandularis proliferans, hamartoma, adenofibromyoma, intramural diverticulosis, and diverticular disease of the gallbladder, but currently GA is approved worldwide [3]. At present, the pathogenesis of GA is not yet clearly understood. It is less common in young people and females tended to be more commonly affected than males. The incidence is about $2.8-5 \%$ of cholecystectomy specimens [2,4]. We present a rare case of diffuse GA type with a complication of cholecystitis.

\section{Case Presentation}

A 51-year-old man presented to the emergency unit with right hypochondriac pain and abdominal distention happening 2 days before. There was no significant medical history. The additional symptoms consisted of fatigue and mild postprandial nausea. Reports showed no vomiting, jaundice, or weight loss. He was febrile with a temperature of $38^{\circ} \mathrm{C}$; other vital signs were unremarkable. His abdomen was soft with tenderness noted in the right hypochondriac region; Murphy's sign was positive. Laboratory tests including AFP, CA19-9, CEA, SGOT, SGPT, bilirubin, transaminases, and alkaline phosphatase were within normal limits. White blood cell were increased slightly by about $12,000 / \mathrm{mm}^{3}$. Ultrasound features included an about $18-$ $20 \mathrm{~mm}$ thickened gallbladder wall, near-total obliteration of the lumen, Rokitansky-Aschoff sinuses, calcification, and comet-tail artifacts (Fig. 1). No obvious color uptake was seen on Doppler evaluation. Computed tomography images showed a diffuse thickened gallbladder wall and inner layer enhancement. Accumulation of fluid and fat stranding surrounding the gallbladder suggested acute inflammation (Fig. 2). The patient underwent cholecystectomy. Gross images of surgical specimens showed diffuse thickening of the gallbladder wall. Histopathology confirmed GA accompanied by inflammation. This diagnosis was confirmed by the histopathologic features of a diffuse thickened wall, presenting Rokitansky-Aschoff sinuses, hyperplasia of collagen fibers, and hypertrophy of smooth muscle; no evidence of malignancy was detected. The patient recovered and was discharged after 5 days. He was followed up for 1 year and did not show any abnormalities.

\section{Discussion}

GA is characterized by excessive epithelial proliferation which gives rise to epithelial infolding within the underlying muscular layer, resulting in gallbladder wall thickening with subsequent formation of intramural diverticulosis lined by mucosal epithelium [5]. Histologically, it is characterized by epithelial and smooth muscle proliferation. The muscular hypertrophy is considered to be caused by increased intraluminal pressure. On microscopy, the hyperplastic smooth muscle cells are accompanied by epithelial invaginations forming Rokitansky-Aschoff sinuses with cholesterol crystals or calcified nodules trapped inside because of chronically elevated intraluminal pressure. The gallbladder epithelium lines may penetrate

\section{Karger'”}




\section{Case Reports in Gastroenterology}

Case Rep Gastroenterol 2021;15:100-107 DOI: 10.1159/000511762

(c) 2021 The Author(s). Published by S. Karger AG, Basel www.karger.com/crg

Hoang et al.: Diffuse Gallbladder Adenomyomatosis with an Inflammatory Complication in an Adult

the subserosa and reach the serosa (Fig. 3). Three types of GA are described: fundal (localized), segmental (annular), and more rarely diffuse (generalized) [6]. The fundal pattern localizes at the fundus of the gallbladder, which presents as a central dimple. The segmental pattern is located in the body of the gallbladder; it separates the gallbladder into two communicating compartments like an hourglass. The diffuse pattern is extremely rare and manifests with thickening of the entire gallbladder wall (Fig. 4) [4-7].

Although GA is usually asymptomatic, it can manifest as abdominal pain or be associated with chronic inflammatory biliary tract disease. GA is mostly detected incidentally by imaging diagnostics and usually requires no treatment. On ultrasound, it appears as a localized or diffuse thickened gallbladder wall with intramural diverticula containing sinus cavities. There can be echogenic or anechoic luminal content in the gallbladder wall. Cholesterol crystals trapped in the sinuses manifest as comet-tail artifacts. Computed tomography and cholangiography are not routinely used in GA. Computed tomography images were useful in our case as they allowed visualization the contrast enhancement pattern and helped to exclude malignant disease of the gallbladder. In clinical routine, magnetic resonance imaging is an important reference examination. Pearl necklace sign, which reveals the presence of RokitanskyAschoff sinuses, is a specific finding of GA at magnetic resonance cholangiopancreatography $[3,7,8]$. The differential diagnosis includes all diseases that cause gallbladder wall thickening, such as xanthogranulomatous cholecystitis, chronic cholecystitis, or gallbladder cancer [5-9].

The relationship between GA and carcinoma is still controversial; some studies proposed that the segmental type of GA preceded the development of gallbladder cancer $[9,10]$. Some more recent research has considered GA and gallbladder cancer to reveal different histological features: adenomyomatosis is characterized by epithelial and smooth muscle proliferation, whereas gallbladder cancer represents cell dysplasia [11]. Currently, GA cannot be considered a premalignant lesion based on available evidence. However, presence of stones and cholecystitis may lead to dysplastic changes and cancer $[4,10]$.

For the treatment of symptomatic GA, an indication for cholecystectomy is necessary. Asymptomatic GA does not require surgery, but the radiological diagnosis must exclude gallbladder malignancy. In our case, the patient presented with acute cholecystitis. Without timely treatment, this can progress to gangrene and perforation [12-14]. For these reasons, in our case, the indication for surgery is given.

\section{Conclusion}

Diffuse GA is a rare benign lesion and can lead to inflammatory complications. It is an entity that can mimic cancer. Therefore, imaging studies play an important role in diagnosis and differentiation. Although we have contributed further knowledge about diffuse GA, it is not fully understood. Future insight studies will be needed to determine more advanced diagnosis techniques, effective treatments, and management methods.

\section{Statement of Ethics}

We reported this case in compliance with the Declaration of Helsinki. Written informed consent was obtained from the patient for publication of his case, including images. The identity of the patient was protected.

\section{Karger'=}


Case Reports in
Gastroenterology

Case Rep Gastroenterol 2021;15:100-107

DOI: $10.1159 / 000511762$

(c) 2021 The Author(s). Published by S. Karger AG, Basel www.karger.com/crg

Hoang et al.: Diffuse Gallbladder Adenomyomatosis with an Inflammatory Complication in an Adult

\section{Conflict of Interest Statement}

The authors have no conflicts of interest to declare.

\section{Funding Sources}

None.

\section{Author Contributions}

All authors contributed equally.

\section{References}

1 Jutras JA. Hyperplastic cholecystoses; Hickey lecture, 1960. Am J Roentgenol Radium Ther Nucl Med. 1960 May;83:795-827.

2 Lin SH, Chang FY, Yang YS, Jin IS, Chen TW. Rare gallbladder adenomyomatosis presenting as atypical cholecystitis: case report. BMC Gastroenterol. 2011 Oct;11:106

3 Hammad AY, Miura JT, Turaga KK, Johnston FM, Hohenwalter MD, Gamblin TC. A literature review of radiological findings to guide the diagnosis of gallbladder adenomyomatosis. HPB (Oxford). 2016 Feb;18(2): 129-35.

4 Pang L, Zhang Y, Wang Y, Kong J. Pathogenesis of gallbladder adenomyomatosis and its relationship with early-stage gallbladder carcinoma: an overview. Braz J Med Biol Res. 2018;51(6):e7411.

5 Bonatti M, Vezzali N, Lombardo F, Ferro F, Zamboni G, Tauber M, et al. Gallbladder adenomyomatosis: imaging findings, tricks and pitfalls. Insights Imaging. $2017 \mathrm{Apr} ; 8(2): 243-53$.

6 Kinoshita H, Ariga H, Shirota J, Sasaki K, Shibukawa Y, Fukuda Y, et al. Combined Fundal and Segmental Adenomyomatosis of the Gallbladder in a Child: A Rare Case Report. Case Rep Pediatr. 2019 Nov;2019: 2659089.

7 Maldjian PD, Ghesani N, Ahmed S, Liu Y. Adenomyomatosis of the gallbladder: another cause for a "hot" gallbladder on 18F-FDG PET. AJR Am J Roentgenol. 2007 Jul;189(1):W36-8.

8 Bang SH, Lee JY, Woo H, Joo I, Lee ES, Han JK, et al. Differentiating between adenomyomatosis and gallbladder cancer: revisiting a comparative study of high-resolution ultrasound, multidetector CT, and MR imaging. Korean J Radiol. 2014 Mar-Apr;15(2):226-34.

9 Nishimura A, Shirai Y, Hatakeyama K. Segmental adenomyomatosis of the gallbladder predisposes to cholecystolithiasis. J Hepatobiliary Pancreat Surg. 2004;11(5):342-7.

10 Kai K, Ide T, Masuda M, Kitahara K, Miyoshi A, Miyazaki K, et al. Clinicopathologic features of advanced gallbladder cancer associated with adenomyomatosis. Virchows Arch. 2011 Dec;459(6):573-80.

11 Akçam M, Buyukyavuz I, Ciriș M, Eriș N. Adenomyomatosis of the gallbladder resembling honeycomb in a child. Eur J Pediatr. 2008 Sep;167(9):1079-81.

12 Parolini F, Indolfi G, Magne MG, Salemme M, Cheli M, Boroni G, et al. Adenomyomatosis of the gallbladder in childhood: A systematic review of the literature and an additional case report. World J Clin Pediatr. 2016 May;5(2):223-7.

13 Mahajan A, Sripathi S. Gallbladder Adenomyomatosis Mimicking Carcinoma: A Diagnostic Dilemma. J Glob Oncol. 2016 Jun;2(5):341-5.

14 Golse N, Lewin M, Rode A, Sebagh M, Mabrut JY. Gallbladder adenomyomatosis: diagnosis and management. J Visc Surg. 2017 Oct;154(5):345-53. 
Case Reports in Gastroenterology
Case Rep Gastroenterol 2021;15:100-107

DOI: $10.1159 / 000511762$

๑ 2021 The Author(s). Published by S. Karger AG, Basel www.karger.com/crg

Hoang et al.: Diffuse Gallbladder Adenomyomatosis with an Inflammatory Complication in an Adult
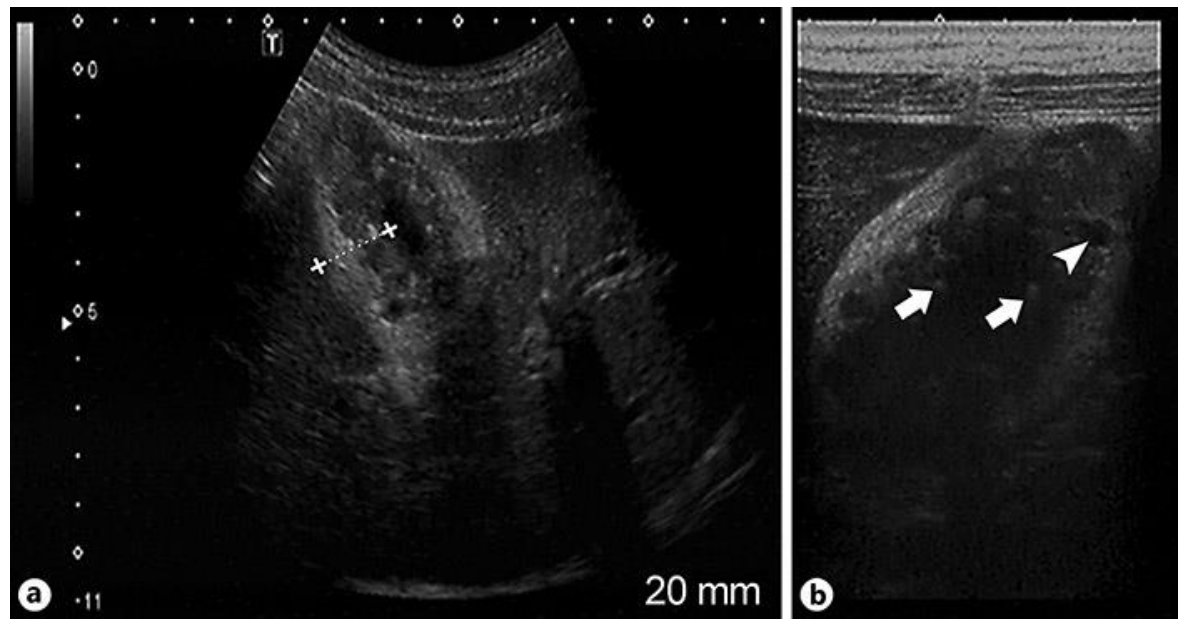

Fig. 1. Ultrasound revealed gallbladder adenomyomatosis using different frequency probes. a Sagittal plane image of the gallbladder with ultrasound transducer converts showed a thickened wall longitudinally, including numerous intramural echogenic foci. $\mathbf{b}$ A longitudinal section of the gallbladder with a linear ultrasound transducer showed comet-tail signs of cholesterol crystals (arrows) deposited in Rokitansky-Aschoff sinuses (arrowhead). 
Case Reports in Gastroenterology
Case Rep Gastroenterol 2021;15:100-107

DOI: $10.1159 / 000511762$

(c) 2021 The Author(s). Published by S. Karger AG, Basel www.karger.com/crg

Hoang et al.: Diffuse Gallbladder Adenomyomatosis with an Inflammatory Complication in an Adult
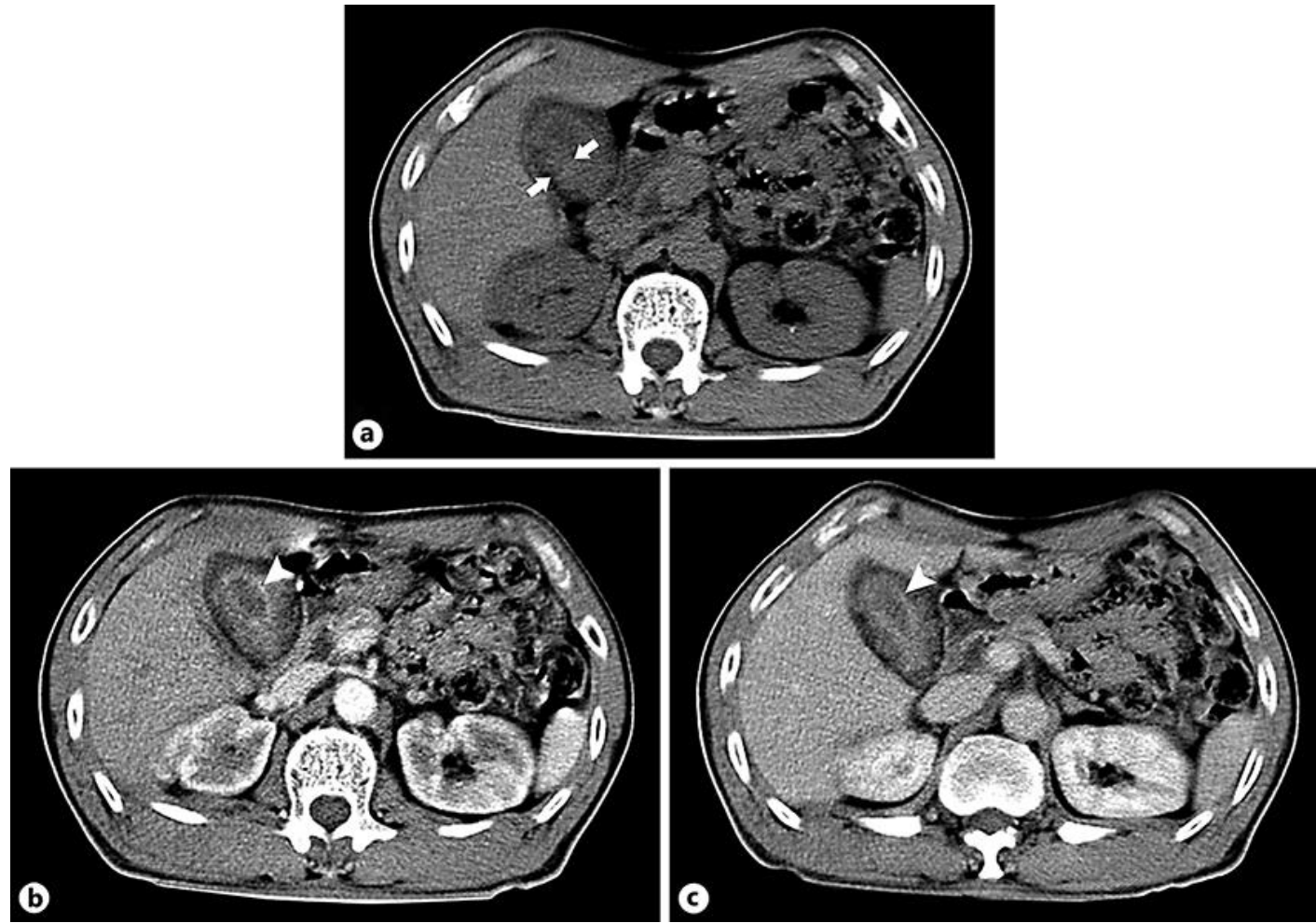

Fig. 2. Axial computed tomography images: unenhanced phase (a) and contrast-enhanced phases with arterial (b) and venous (c) gallbladder adenomyomatosis showing diffuse gallbladder wall thickening (arrows) with intact mucosal enhancement line (arrowheads). 
Case Reports in Gastroenterology
Case Rep Gastroenterol 2021;15:100-107

DOI: 10.1159/000511762

(c) 2021 The Author(s). Published by S. Karger AG, Basel www.karger.com/crg

Hoang et al.: Diffuse Gallbladder Adenomyomatosis with an Inflammatory Complication in an Adult
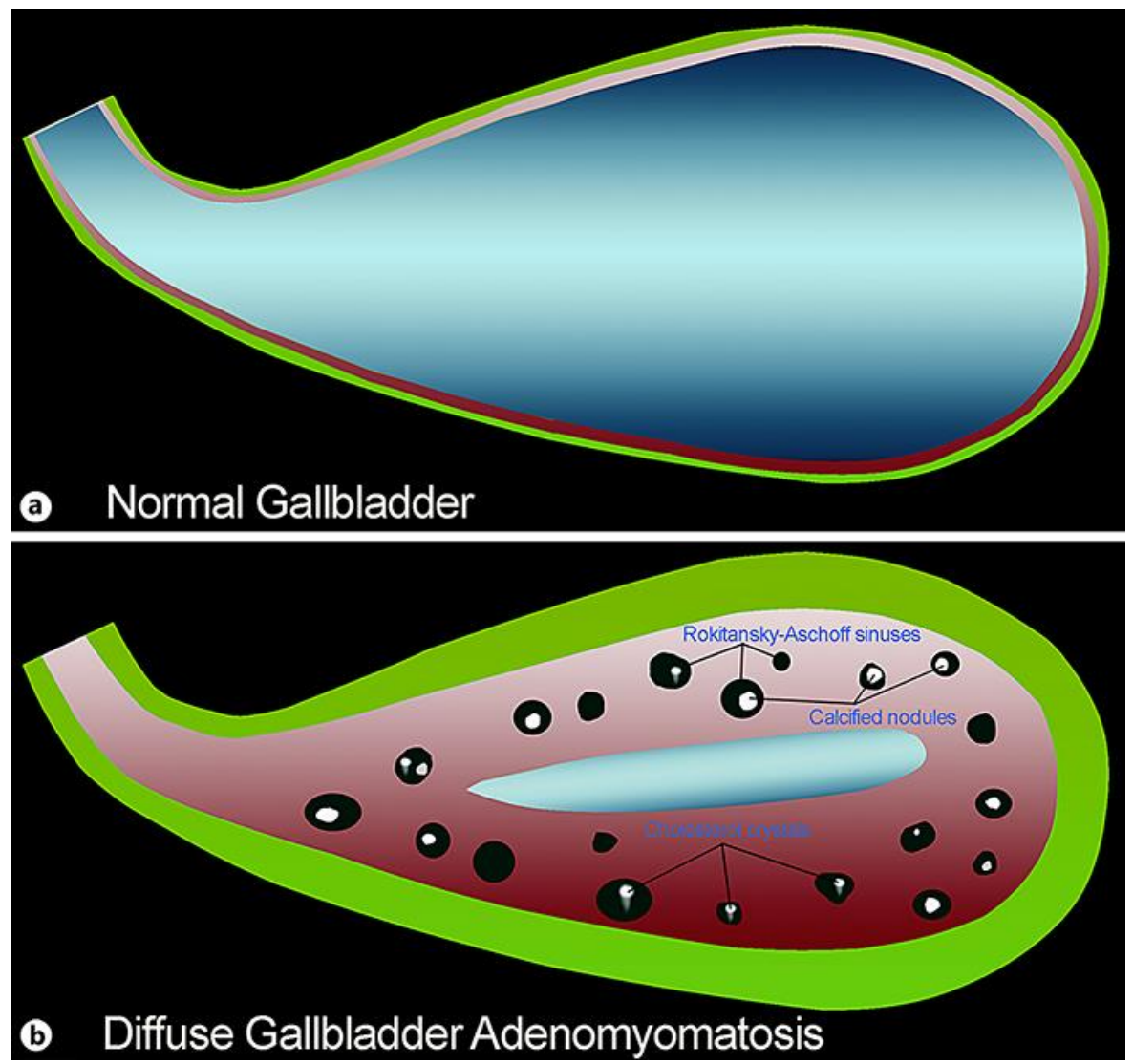

Fig. 3. Illustration of a normal gallbladder (a) and of diffuse gallbladder adenomyomatosis (b) 
Case Reports in Gastroenterology

a

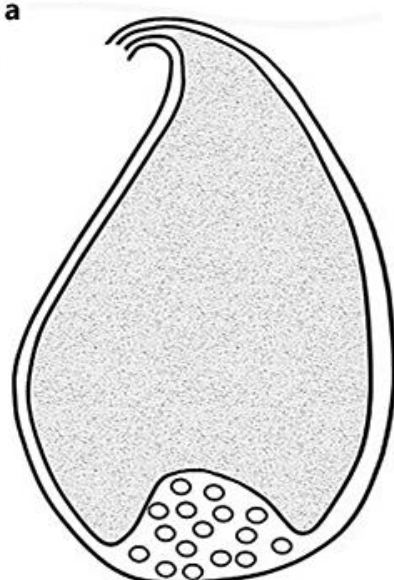

Fundal (localized)
Case Rep Gastroenterol 2021;15:100-107 DOI: $10.1159 / 000511762$

(c) 2021 The Author(s). Published by S. Karger AG, Basel www.karger.com/crg

Hoang et al.: Diffuse Gallbladder Adenomyomatosis with an Inflammatory Complication in an Adult

b

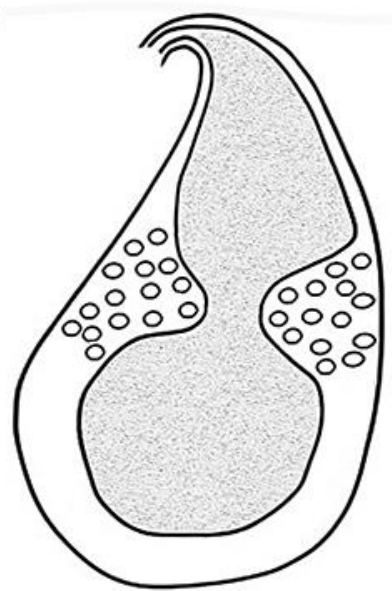

Segmental (annular)

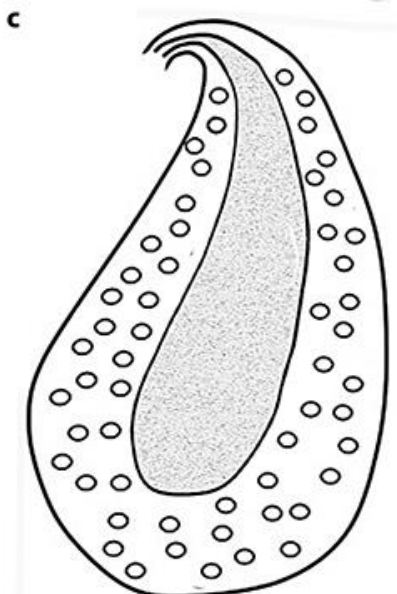

Generalized (diffuse)

Fig. 4. Illustration of three types of gallbladder adenomyomatosis. a The fundal type located in the fundus of the gallbladder. $\mathbf{b}$ The segmental type located in the body of the gallbladder which separates the gallbladder into two communicating compartments like an hourglass. c The diffuse type manifests thickening of the entire wall of the gallbladder. 